\title{
DIMENSIONS OF THE MARKET RISK
}

\author{
Marcela-Cornelia Danu \\ "Vasile Alecsandri” University of Bacău \\ marceladanu@ub.ro
}

\begin{abstract}
The present work presents the concept approach and the types of the market risks, considering the representatives of the two correlative dimensions of the market: the supply and the demand. This approach dissociates from the other ways to define and to manage the market risks by the message that it communicates: all the types of risk caused by the market activities are market risks. These are anthropic risks, based on information and decision. From the point of view of source, the market risks or the decisional risks have the actions of the deciders (natural person or legal person) to achieving the personal goals or mission or the objectives of the firm which they represent. The market risks are those which pose a threat to the attainment of the major objectives or purposes and to maximizing of advantages: the utility for the consumer and profit for the enterprise. The results of the dynamic interdependences are determined by the optimal management of each type of risk, taking into account the system of risks and the potential for transformation of the risk-cause in risk-effect and vice versa.
\end{abstract}

\section{Keywords}

the market risk; risks of the consumer; the risks of the suppliers; perceived risk; assumed risk

\section{JEL Classification}

D11; D21; L21; M21; M31

\section{The market risk in the context of the fundamental objectives of the market exponents}

While, for the most firms, the fundamental objective is to maximizing the profit, the most of the actions which generating the entrepreneurial risks have as source this objective (Danu, 2001). From the point of view of risks of the consumer, they have as essential purpose the maximizing satisfaction of the consumption needs by using of the limited resources it has at its disposal, and therefore maximizing the economic utility on the basis of the principle of hedonist.

The market risk, entrepreneurial type shall be determined, in the main, by (Colson, 1995):

- decisions of the public bodies in the area of taxation;

- techniques of production - informatics system, research and development, etc.;

- $\quad$ structural factors in the business - organization, absorption, merger, etc.;

- $\quad$ characteristics of the reference market - diversification, competition, context;

- material, financial, human and informational potential of the enterprises.

The market risks, risks of the consumer type are influenced by the direct factors such as:

- $\quad$ nature and situation of the consumer;

- $\quad$ value and accessibility of information in the purchasing process;

- the type of the decision be taken into account.

In general, the characteristics of the market risks are: 
- represents the resultant of the deciders (entrepreneurs or consumers), deriving from their rational choice, given the attention to maximizing the effects and minimizing the efforts. Decisions taken regarding the risk are different from one company to another, from one consumer to another, depending on the specific conditions that make available the internal environment of the company, the relationships to the elements of external environment, due to the personality of the decider (as a consumer or individual entrepreneur), its qualities, skills, and last but not least to its mental, emotional, affective availability, to accept it or not, to be indifferent to risk.

- $\quad$ the market risk is separable, both the consumer and the enterprise, having the possibility to decide his assumption by allocating the adequate budgets (for example, at a firm, to launch a new product, to organize a promotional campain, to realize a research project, etc.);

- the effects of these risks are quantifiable and predictable over time, so that deciders can meet with a relatively high probability, the positive or negative implications involved in achieving them. For example, once it is taken risky decision to launch a new product, shall constitute the budget dedicated to this activity, shall be carried out the prototype technical and the acceptability testing. If the trials are fairly conducted and accurately expresses the reality (how the consumer perceives the new product, image and the degree of acceptability of the product to consumers), the enterprise has an possibility to do eventual correctives in terms of technical parameters, qualitative parameters, from point of view of prices, etc., or may decide even to abandon the product before the commitment of some expensive investments;

- the market risks can be, and are controllable. The treatment of these risks is done in the case of the entrepreneurial risks by applying the financial, managerial, marketing, human resources strategies, etc., and in the situation of the consumer, through the permanent information as far as possible, - complete, correct, realistic information and by the education through media credibility;

The range of the market risks, whether they are entrepreneurial, either with the base to the consumer, it is extremely vast, concretely no sector of activity or purchase made by the consumer, in which such risks to be absent. Regarding to the entrepreneurial risks, it should be noted that, here included are those which related to the purchase decision, therefore as a consumer. The motivation to include the risk of buying into this group and not in the group of the consumer, shall be given, on the one hand, of the decisional element belonging the enterprise, and on the other hand, because the act of consumption specific of the enterprise is not its goal; the main objective is the achievement of maximum profit.

\section{Risks of the consumer}

The needs felt, the desired values of the consumer are final aims. Whether they are concrete or abstract nature, they may be satisfied, usually, through a wide range of possibilities (in particular the abstract) but their realisation, in some cases, it is not possible (Blythe, 1998). This is the reason for which the consumer shall specify series of secondary purposes that provides the necessary structure to make the purchasing decision or in other words, establish priorities. Previous experience of the subject is important; those without previous experience will difficulty rank the purposes, will be repeated attempts, many unsuccessful, will assume a series of hazards, which unfortunately will have a negative impact on them.

The process to find the best solution to problems of sale - purchase is influenced by the information about the product or service, a level which the consumer can ensure 
by experience or/and the degree of interest in connection with the product or with the process of choice.

For the inexperienced buyer revolves a great risk attached to the purchasing of product. He has, by definition, summaries specialized knowledge about the products they intend to purchase them. With motivation of establishment of the hierarchy of purposes, the consumers will try to reduce the risk, in this way each secondary purpose having a certain percentage of risk. The risks perceived by the consumers in the process of buying are: (Roselius, 1971):

- physical risks caused by the products whose consumption or use may pose hazards to health, environment, etc. For example, buying a car with brake system failure, a hair dryer or a mixer with technical defects, etc.

- financial risks caused by the loss, wasting money either by replacement or repair of a new purchased product either his purchasing at a unreasonably, high price. For example, buying a car that crashes quickly, or watching a theatre, performance below the expected value to the consumer, etc.

- the risk of lost time due to the difficult acquisition, product failure, times affected by the consumer returns to the supplier or manufacturer, repair, temporary replacements, etc.

- the risk of expected performance. For example, purchasing the book by a brand whose contents are not up to expectations, a medication whose effects are not the expected, etc.

- $\quad$ risk of image (psycho-social), reflecting consumers ' disappointment towards himself in connection with the purchase or weakness into the social environment. For example, buying the clothes in a circle of friends who appreciate the negative, or a property located in an area with poor reputation, etc.

The only viable way to reduce the risk perceived by the consumer before the purchase decision, is the information under all forms accessible and credible. Recourse to the informations is all the more important as perceived risk is higher. Economic theory of information allowed the conceptualization of the problem, for example, in the case in which the consumer is exposed only to the financial risk, caused by purchasing of the product at a price too high.

By reporting decreasing the purchasing price, which would necessitate supplementary information, to the additional information using, and by weighting it with desired purchase importance, we can compare the result obtained with the cost (measured in time devoted additional information) driven by obtaining the supplement information. Additional information will be justified only if hoped gain exceeds the cost of the supplement of information. Conclusions:

- for product or service placed on the top of hierarchy of preferences or priorities, the additional information are cost effective;

- the greater inertia at the bigger consumers toward individual consumers;

- consumers for which budget does not allow always, or often, additional information, and for whom time is assigned with a very high value, will not consider such a model.

Consumers have a wide range and variety of methods for reducing the risk. In accordance with the model of Roselius, focused on purchasing process of the consumer, have been reflected a few ways to reduce risk of the consumer, in relation to financial risk, risk of loss time, physical risk, psychologically risk (risk of image). The proposed methods to reduce or even avoid the risk are:

1. choosing a recommended brand by experts or people from the individual's entourage, celebrities, etc.;

2. loyalty for the recognized brand, which the consumer already knowing the produced satisfaction; 
3. choosing the product or the mark having a reputation, prestige, so having a brand;

4. personal testing;

5. the reputation of point of selling, buying a mark distributed from a favorable image store;

6. evaluation of the samples provided free of charge to consumers in the prepurchase stage;

7. guarantee the change of goods or refund the value;

8. use of tested brands, officially approved by the competent body;

9. visits to the various points of sale and compare the characteristics of several brands;

10. buying a brand of a model's more expensive or more elaborate;

11. opinion approved (communication of 'word of mouth'), request the opinion of others on products or presented brands.

The results of the carried out research have highlighted, in summary, that individuals front attachment brand known, its image in the producing or distributors firms are decisive, regardless of the type of risk to which we are referring.
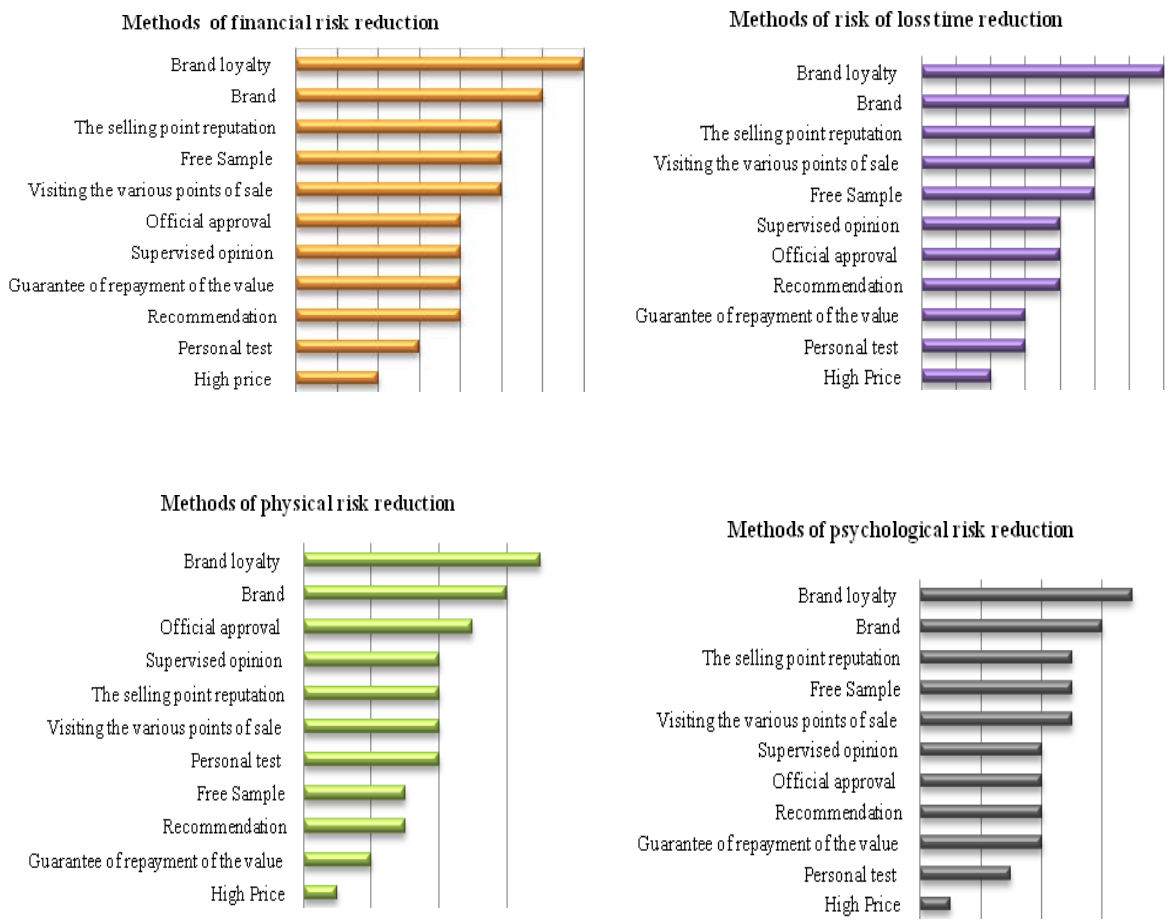

Figure 1 Methods of reducing the risk perceived in the decision to purchase Source: Processed Roselius, T. (1971), Consumer Rankings of Risks Reduction Methods, Journal of Marketing, Vol. 35 (January, 1971), pp. 56-61.

Other detached conclusions are:

- the least approved are: the personnel test, guaranteeing repayment of the value of the goods and the acquisition due to the high price;

- this research has highlighted the way in which consumers use different methods of risk reduction based on conjectural statements; 
- for physical risk, only brand loyalty, purchase a recognized brand and official approval provided favorable answers.

Roselius, his first research of this kind, however, require additions and nuanced interpretations taking into account the various types of products or services, new types of risk specific to the current economy and conjectural statements different from a geographic, economic, political, to another.

To reduce the risk and simplifying the process of decision making, 'the experience' consumers switch from search phase, to the assessment, culminating with the selection of the optimal alternative.

In the phase of search, the consumer is informed to the desired product, stores where he can purchase, or the place where the service is supplied; the sources of information must be relevant, reliable, knowledgeable. To minimise the risks at the stage of the assessment, the consumer must take into consideration the key criteria that defines the product or service in line with its expectations, the negative criteria - which should be insisted, and the significant differences compared to the products that satisfy the same need. In the last step, the selection, as consumer expectations to be better met, and the agreed to be as close as possible to the one he want (minimum tolerance), is aimed at: (a) in the case of purchase of known, familiar products: operation of the product to be the best; the choice of approved alternatives by the circle of knowledge, friends, family; taking into account the promotion measures designed to inform, persuade and remind purchase that product; and (b) in a situation of purchase of new products: caution, behavior observation product to other buyers, recommendation, supervised opinion.

Making the decision to purchase, the perceived risk is one of the factors that may arise and change the intent of purchase. Perceived risk varies according to the money allocated to the purchase, acquisition and insecurity of self-confidence that the buyer (Kotler, 1998). Given the feelings of apprehension, uncertainty, risk which the consumer will feel in connection with the acquisition of the product, the task of the deciders is to find factors leading to enforcement of these feelings (the anticipated level of income of the family, the estimated cost and the expected advantages of that product, loss of job, etc.), providing information and support to minimize the perceived risk.

All purchases, and particularly those important, results in the post-purchase with the so-called cognitive dissonance or discomfort which means that, as a matter of fact, the consumer is not fully satisfied with his purchase. It is, therefore, of the negative dimension of the assuming risk, time in which the consumer under the empire of the certain mental statuses and influenced by a number of social, cultural, personal factors (age, occupation, lifestyle, income, personality), is dissatisfied with certain shortcomings of the selected mark and by the fact that he lost the advantages that it can give he buying other brands (cost of opportunity). The managers of producing and commercial firms must know very well the needs of the consumer, to anticipate changes in tastes, preferences, generally all of the factors that could influence purchasing behaviour, with a view to launching attractive offers on the target market (Danu, 2001).

An interesting aspect of the risk in the decision-making process of purchase, it is about the new products. As a result of inter-personal communication, of a consumer specific traits, as well as intrinsic characteristics of the new products, the people they adopt differently. Of these, the consumers placed in innovators category are the most interesting for the enterprise and to the success or failure of product on the market. The innovators are regarded as adventurers, looking for new ideas, assume all risks in connection with that product, to any of their size. Early buyers quickly adopt the new ideas, but assuming risk is more cautious. Anyway, these two categories of consumer assumes most of the risk, but for the company are the first signs of confirmation or 
cancellation of the product from the market and the first creators of income for that product. Most of the early shows wariness and most of the late show skepticism in the purchase decision. The laters, strongly attached to tradition, customs, habits, they are suspicious in the face of change, adopting the product just after he became part of the tradition. Thus, in the decision-making process of buying new products, taking into account the heterogeneous structure of solvent demand, the assumed risk decrease to the last category of the product consumer - the laters.

The perceived risk by the consumer in the purchasing process has many more sides than those highlighted here; variety of situations, places and times in which manifests the intentions of buying of the market with many types and distinct segments, creates as many particular cases of the manifestation of the risks.

In the abundant markets, in which the demand for the products and services is wide and diverse, the risks encountered by the consumer shall not be less than those assumed by consumer located on a poor market but the chances for achieving them and the severity of consequences, if to achieve them, are smaller. Low diversification, the impermeability to new, low competition, etc. - places the consumer face of the few alternatives to choose from where, the greater risks undertaken. For goods breadline necessary, the consumer perceives low or ignore potential risks which may assume by their acquisition; in the case of the other, the purchase decision follows a longer or shorter depending on the characteristics of the product, of the consumer and not in the last row of the environment in which coexist both representatives of the demand as well as those of the supply.

\section{Risks of the supplier}

If to the consumer, the fundamental purpose is maximizing the utility, in the case of the supplier - producer or merchant, he wants to ensure continuing of his business, not at the limit of survival, but by maximizing profits. In achieving this goal, the entrepreneur has encountered a number of risks, some of them caused by the action of the natural forces, environmental variables, part of the internal source of the enterprise.

To be able to develop and deploy at the firm, the strategic viable plans, folded on diverse requirements of the market, the managers must first identify the opportunities and threats from the external environment, and the strengths and weaknesses, 'offered' by the internal environment. Threats or risks faced by the company from the outside, can be (Kotler, 1998):

- the actions of the competition. For example, a competitor announces the launch of a new product, backed by a offensive promotional campaign;

- the difficulties, conflicts, pressure at the level of distribution channels. Increased competition at the level of distribution channels or within the same channel or in different sequences thereof, may negatively influence the possibilities of distribution of company products;

- the demographic changes, migrations of the population from one area to another, with repercussions in decreasing areas of market and increase another, changes in age structure, place of residence, level of education, socio-professional level, etc.;

- the unfavourable social and political conjuncture. In countries where political instability is high and protest movements are frequent, the activity of the firms is heavily affected and the major purposes, difficult to achieve.

The mission of the managers is to predict the probability of each of these risks and the effects they may cause. Some of these risks are threats for some businesses and occasions or opportunities for others. 
Among the weaknesses of the firm which influence it success, we can mention:

- low position in the reference market;

- the range of products disparity to the real requirements of the market (too high or too low);

- $\quad$ reduced sale in the large market;

- low promotional activity of the products or services;

- $\quad$ bad management, oriented toward the past, based on intuition and quackery, etc.

In the elaboration of development strategies aimed at increasing profitability, entrepreneurs have at their disposal, the possibilities (Kotler, 1998): increasing productivity and increasing the volume of activity. And for one and for the other alternative action, the risks that may obstruct the fulfilment the purpose of maximizing profits, are numerous.

If it follows the path of productivity growth, risks that may lead to deviations from the objectives, are stemming from difficulty or impossibility of reducing costs (investment, fixed, variable) or the increase in margins (the change of the range of products and services, rising prices, rising the adding value). In terms to reducing the costs - fixed, variables and investments, possibly by restricting activity or by accelerating operational processes, among the risks that influence these action lines are: old production technologies, with high degree of wear, non-performing, weak productive, clunky, arhythmic supplies, with considerable expense, capital immobilized in oversized of the raw materials, slow operations of production and selling, poorly qualified manpower, hardly adaptable to the new organizational structures and inadequate production, bureaucratic and inflexible management, with conservative tint etc. It should be noted that risks referred to are not spontaneously and for the most part are not resultant of immediate decision: they reflect ways of thinking and action by the managers, their ability to respond to demands of the environment and to a dynamic market. All of these risks are the result of only a single type of risk: the risk of a lead, organize, and schedule as much as possible the production and the human resources.

Changing the assorted structure, the appropriateness of the structure to the peculiarities of the market, to the characteristics of the targeted market segment, may be limited to risks as: the technologies that do not allow the expansion, increasing the range of products, or involving additional costs not recovered through revenue, estimated, hence the impossibility of increasing the profitability; specific risk of marketing researches - aimed to the knowledge of the market, its current requirements and anticipating the future, unfavorable economic conditions for optimal supply, consistent with the production, deterioration of the international economic relations of the company with other companies with the traditional internal or external partners, unfit political conjecture to establish long-standing relationships with foreign partners both on the import of raw materials as well as to ensure market selling products, etc. , the risk of legislative, non nepermissive to the enlargement and development range of activities of the firm, etc.

Raising the prices, alternatively of the increase in the profit margin, is possible only if it is used with caution, taking into account the nature of the goods or service, the competitive context and it evolution (in numerical terms but also of the action force), changing the mindsets of consumers, the purchasing power of the reference market. In this regard, to implement the strategic approach, the risk of competition and the risk of the consumer's image are the most significant types of risk which must be taken into account.

Adding the value to a product or a service should be the strengths of the strategy of the company's. It is imposed by the diverse needs of the consumers and a stronger competitive environment, in which the identification of the product and the 
differentiation of the mass of similar products on the market are by far the most important objectives to be attained in the direction of maximizing profitability. As in the case of application of the other measures to growing the profit, the technological risks, the financial risks, the marketing risk, may strongly determine the attainment of the continuity and success of the company on the market.

Increasing the profitability may also occur by increasing the volume of activity of the company. In turn, this has as sources of achievement: the behaviour towards competitors (winning the competition, purchasing customers competitors), increase of production capacities, but also creative activities, such as: addressing to the new segments of the market, to the new markets, renewing and diversifying production. As obstacles to the achieving these objectives, the risks that interferes are: risk of quality of products, various types of financial risk, risks arising from research and development activities of the company, risk of marketing, social risks, etc.

Increasing the profitability of the firm can be accomplished by extending its activity beyond national area the more the limited increasing of the internal market, increasing competition at this market and increase the risk of operating on a particular market (determined by differen cycles which characterise the political and economical life of a country), oblige the companies which are willing to ensure high profitability, to enter on the international market too. At the same time, it manifest the assuming of the risks which involves all the firms in the system of the world economy. Managers need to anticipate the risks, the obstacles to conduct the operations on foreign markets. Main risks which may adversely affect the company on the international market are (Sasu, 1998):

very large foreign debts. High rates of indebtedness, inflation, unemployment in some countries have contributed to political instability and currency, restricting trade and business exposure to a number of risks. The inability of these countries is an obstacle for supplier firms.

- the instability of the exchange rate of a currency influences the competitiveness of the company operating on the international market. In a situation where the national currency is weak, it is favourable to the export activity; if on the contrary the national currency is strong, domestic competition will be stimulated.

- instability of Governments and the restrictive practices imposed by them. The unstable economic environment of the countries with favorable potential of the market involves high risks of expropriation, nationalization, repatriation of profits. Also for Governments that impose certain restrictions, risks deriving from these practices are: a certain degree of control over the activity of the firm, the majority participation in the capital of domestic enterprises, using the national employment, limitations to the transfer of technology, compliance with local rules, limiting production intended for export, etc. Such practices are in some emerging development countries while the developed countries impose more qualitative conditions. In addition to non-tariff barriers designed to protect the national industries, for the company that does business on the international market are tariff barriers (large import duties).

- the cultural conflicts, starting with those pertaining to language and ending with those due to traditions, the local customs require researches of the international relationships system. These barriers have effects, such as: the difficulties of communication with a foreign partner, the impossibility of standardisation of products and the need to adapt it to the specific requirements of the local population.

wars, terrorism, and corruption. The local conflicts, increasing proportions of the terrorism in many places of the world, the corruption of officials involved in commercial transactions between countries, these are political risk, social risk (or combined) many of them having the economic motivation, affecting the involvement 
of companies in international business. To these are added the technological piracy which endanger the image of firms.

Risk of image is a different type of significant risk in the current context of economic world system. Four of the five directors believe that their company reputation is the most valuable asset (European Risk Briefing, 2013). However, against the background of changes generated by economic and financial crisis world, they believe that the trend is to increase the risks associated with the reputation. Moreover, increasing the rate of threats over the reputation of the firm increases the difficulty to manage it. The globalization and the legal system are considered to be the main sources of risk of image to firms.

These are just some of the problems of contemporary society in which the risks with small or medium intensity and severity, manifested at the local level or in relatively small areas, may turn in risks of great gravity and intensity at regional or even global scale. Once is assumed the task to extending abroad in order to obtain a profit, managers need to adopt an active attitude, facing to the market, aimed to the identification and anticipation of the foreign consumers needs. To overcome the physical national borders, the firm must know whether it will be able to do it and on the thorough knowledge of the peculiarities and characteristics of foreign consumer, whether it will be able to communicate with consumer and will be able to receive his feed-back and if will be able to adapt to the foreign business environment. And because the answers to his questions will evidently be placed under the sign of uncertainty, insecurity, he will be victorious assumed or defeated assumed of all those risks. The ability, competence and spirit of successful business depends on his undertaking; successful which does not mean survival but performance and profitability.

If in estimating of the risks specific to the consumer, we have had in view the way he perceives risks, their degree of diversity, the intensity and the effects on individual, in the case of enterprises, making decisions becomes possible by appealing to a wide range of methods and techniques of decision-making, which are assigned to a particular model of decision-making, differential treatment in relation to the typology of the involved situation.

\section{Conclusions}

Regardless of whether we find ourselves in the situation of the consumer, or in the firm situation, supplier of goods and services, they are both in double hypostasis: to assume the risk and "to create" the risk. The consumer and the firm have well defined targets. But reaching them is difficult and fraught with dangers; some of them are beyond of the decider, others partly or wholly involved him. The end result is often difficult to anticipate.

Real life and not a theoretical existence demonstrates that measurements, quantifications are necessary, but not sufficient when we evaluate the impact of those unwanted danger upon us as individuals. The actual costs of risks are infinitely greater than those which are strictly subject to the financial sphere; larger through the time to which they relate, and by spreading them in space, and by the effect of propagation on the other risks, with other costs. However, the life is not fulfilling, may not tends toward perfection, without incorporation and the taking over him. 


\section{References}

ACE Group (2013), Reputation at Risk, ACE European Risk Briefing, available at http://www.acegroup.com/global-assets/documents/Europe-

Corporate/Thought-Leadership/ace_reputation_at_risk_july_2013.pdf

Blythe, J., (1998), Comportamentul consumatorului, Editura Teora, Bucureşti.

Colson, G. (1995), Gestion du Risque, E.A.A., Paris.

Danu, M. C. (2001), Riscul în afaceri, Editura Plumb, Bacău.

Kotler, Ph. (1998), Principiile marketingului, Editura Teora, București.

Roselius, T. (1971), Consumer Rankings of Risks Reduction Methods, Journal of Marketing, Vol. 35 (January, 1971), pp. 56-61.

Sasu, C. (1998), Marketing internațional, Editura Polirom, Iași. 